\title{
Особенности состава лёгочного микробиома в связи с цитоге- нетическими изменениями у больных аденокарциномой лёгкого
}

\author{
() В.Ю. Буслаев ${ }^{1^{*}}$, В.И. Минина ${ }^{1,2}$, В.Г. Дружинин ${ }^{2}$, В.П. Волобаев ${ }^{2}$ Е.Д. Баранова ${ }^{2}$, \\ П.С. Деменков ${ }^{3}$ \\ ${ }^{1}$ ФИЦ угля и углехимии Сибирского отделения Российской академии наук, Инсти- \\ тут экологии человека \\ Россия, 650000 г. Кемерово, проспект Советский, 18 \\ ${ }^{2}$ Кемеровский государственный университет \\ Россия, 650000 г.Кемерово, улица Красная, 6 \\ ${ }^{3}$ ФИЦ институт цитологии и генетики Сибирского отделения Российской акаде- \\ мии наук \\ Россия, 630000 г. Новосибирск, проспект Академика Коптюга, 2 \\ *E-mail: vladislasbus2358@yandex.ru
}

В настоящее время активно рассматривается роль изменений состава микробиоты в развитии многочисленных патологий, в том числе и связанных со злокачественными новообразованиями. Доноры с высоким уровнем хромосомных повреждений (выше 3\%) характеризовались снижением численности представителей бактериального рода Peptostreptococcus. Данное исследование позволило установить и охарактеризовать специфический состав легочной микрофлоры при аденокарциноме легкого и определить ассоциацию его изменения с высоким уровнем повреждений генома в соматических клетках организма-хозяина.

Ключевые слова: рак лёгкого; аденокарцинома; микробиом; хромосомные аберрации.

Рак лёгкого (РЛ) является онкологическим заболеванием с высоким уровнем смертности [1]. К основным фракторам риска развития РЛ относятся курение, воздействие окружающей среды и генетическая предрасположенность. Организм человека представляет собой экологическую нишу для обитания бактерий, вирусов и грибов. Сложные сообщества микроорганизмов фрормируют микробиоту человека. В настоящее время наблюдается увеличение числа научных работ о свойствах легочной микробиоты, в особенности её бактериального компонента. Действие фракторов внешней среды, генетические особенности могут влиять на баланс микробных сообществ, которые сформировались в течение всей жизни. Микроорганизмы используют множественные стратегии для обеспечения своей выживаемости, в частности с помощью продукции генотоксинов [2]. Развитие повреждений генома организма-хозяина может прямо или опосредовано зависеть от особенностей таксономического состава бактериальных сообществ. В качестве индикатора негативного воздействия на геном используются показатели частоты хромосомных аберраций (XА) в соматических клетках.

В данной работе было поставлено исследование таксономического состава легочной микробиоты в связи с частотой повреждений генома в соматических клетках (лимфоцитах крови) у пациентов и здоровых индивидов. Для реализации данной цели выполнялись следующие задачи: сопоставление профилей легочной микробиоты и уровня цитогенетических повреждений пациентов с аденокарциномой и здоровых доноров. 
Выявление таксонов, ассоциированных с развитием цитогенетических повреждений в составе лимфоцитов периферической крови.

В качестве материала для исследования были использованы образцы мокроты и периферической крови, взятые у 15 больных РЛ (сбор образцов производился до лечения, гистологически подтвержденный диагноз - аденокарцинома легкого) и 15 здоровых индивидов мужского пола, близкого возраста (57 лет) и статуса курения (50 \% курильщиков в обеих группах).

Бактериальная ДНК выделялась из образцов мокроты с применением коммерческих наборов FastDNA Spin Kit For Soil (MP Biomedicals). Подготовку бактериальной ДНК для секвенирования осуществляли согласно протоколу 16S Metagenomic Sequencing Library Preparation, рекомендованномy Illumina для секвенаторов MiSeq. Приготовление материала для секвенирования было осуществлено путём амплификации V3-V4 вариабельных участков генов $16 \mathrm{~S}$ рPHК. Первый раунд амплификации осуществлялся с использованием целевых праймеров, второй раунд проводился для двойного индексирования образцов. Дальнейшую подготовку к секвенированию и секвенирование осуществляли с использованием набора MiSeq Reagent Kit v2 (200 циклов) и прибора MiSeq (Illumina, США) согласно рекомендациям производителя. Биоинформатическая обработка полученных данных производилась при помощи пакета программ QIIME2. B качестве основных репозиториев нуклеотидных последовательностей прокариот были использованы рефреренсные базы данных SILVA и Greengenes.

Для получения хромосомных препаратов для оценки ХА использовали классический полумикрометод культивирования клеток крови. От каждого индивида анализировали 200 метафазных пластинок. Уровень ХА оценивали как отношение общего количества аберраций хромосом к числу проанализированных метафаз. За повышенный уровень XА принимали значение более $3 \%$ согласно проведенному ранее исследованию на большой репрезентативной выборке [Minina et al., 2018]. Статистическая обработка данных осуществлялась с использованием программы «Statsoft STATISTICA 10.0». Сравнение двух независимых групп производилось методами непараметрической статистики с учетом U-критерия Манна-Уитни.

Анализ цитогенетических данных указал на повышенную частоту ХА в клетках крови больных с РЛ легкого по сравнению со здоровыми индивидами $(4,83 \pm 3,56 \%$ против $2,07 \pm 1,03 \% ; p=0,002)$, что согласуется с результатами ранее выполненного исследования [3]. При сопоставлении показателей состава легочной микрофлоры у пациентов и здоровых индивидов, значимые различия были получены для бактерий родов Oribacterium, Capnocytophaga, Gemella, Rothia, Bacillus, Clostridium и Actinomyces (Табл.).

Ранее уже проводились исследования специфики состава легочной микробиоты у больных раком легкого с определенной гистопатологической формой. Было отмечено, что бактериальные рода Acinetobacter, Propionibacterium, Phenylobacterium, Brevundimonas и Staphylococcus ассоциированы с аденокарциномой легкого [4]. Недавнее исследование мокроты больных РЛ (смешанная по гистологическим формам РЛ группа) указало на возможность использования данных легочной микробиоты для диагностики РЛ в связи повышением уровня ХА в лимфоцитах крови [5]. Было установлено, что в группе доноров с высокой частотой ХА была ниже частота встречаемости бактерий рода Atopobium и выше частота Alloprevotella. Кроме того, были выявлены различия микробиоты у курящих и некурящих индивидов. У здоровых курящих доноров бактерии рода Neisseria регистрировались реже, чем у некурящих $(0,39 \pm 0,99$ vs $1,82 \pm$ $2,54 \% p=0,03)$. 
Таблица. Сопоставление профилей легочной микрофлоры.

\begin{tabular}{|c|c|c|c|}
\hline Таксон & $\begin{array}{l}\text { Пациенты с адено- } \\
\text { карциномой } \\
(\%)\end{array}$ & $\begin{array}{l}\text { Здоровые ин- } \\
\text { дивиды } \\
\text { (\%) }\end{array}$ & $p$-value \\
\hline Oribacterium & $0,80 \pm 0,77$ & $0,27 \pm 0,46$ & 0,043 \\
\hline Capnocytophaga & $1,87 \pm 4,02$ & $0,20 \pm 0,41$ & 0,026 \\
\hline Gemella & $2,87 \pm 2,26$ & $1,07 \pm 0,96$ & 0,026 \\
\hline Rothia & $1,67 \pm 1,35$ & $0,47 \pm 0,52$ & 0,011 \\
\hline Bacillus & $2,87 \pm 2,26$ & $1,00 \pm 1,00$ & 0,020 \\
\hline Clostridium & $0,93 \pm 0,80$ & $0,33 \pm 0,49$ & 0,032 \\
\hline Actinomyces & $2,00 \pm 1,77$ & $0,53 \pm 1,60$ & 0,001 \\
\hline \multicolumn{4}{|c|}{$\begin{array}{l}\text { Примечание: В таблице представлены относительные процентные содержания } \\
\text { таксонов при наличии статистически значимых различий между группами срав- } \\
\text { нения }(p<0,05) \text {. }\end{array}$} \\
\hline
\end{tabular}

В нашем исследовании в микробиоте больных аденокарциномой легкого с повышенным уровнем ХА статистически значимо реже регистрировались представители таксона Peptostreptococcus $(0,11 \pm 0,33 \%$, vs $0,83 \pm 0,75 \% \quad p=0,03)$. Это может быть обусловлено тем, что бактерии рода Peptostreptococcus могут снижать воспалительный процесс благодаря синтезу метаболитов индоакриловой кислоты [6]. У курящих индивидов наблюдалось снижение численности бактерий рода Neisseria по сравнению с некурящими $(0,50 \pm 1,29$ vs $3,06 \pm 6,38 \%, p=0,04)$ в группах больных и здоровых обследованных, что согласуется с результатами ранее выполненных исследований. Данное явление обусловлено ингибирующими эффектами табачного дыма на рост данных микроорганизмов [7].

В результате проведенного исследования были выявлены значимые различия профиля легочной микробиоты у пациентов с аденокарциномой легкого и здоровых индивидов. Изменение качественных и количественных показателей бактериальных таксонов следует отнести к возможным механизмам развития рака лёгкого. Развитие повреждений генома может потенциально быть связано с особенностями взаимодействий бактерий с компонентами иммунитета организма-хозяина.

Работа выполнена при поддержке гранта РФФИ 20-44-420012 p_а. 


\section{Литература}

1. Barta J.A., Powell C.A., Wisnivesky J.P. Global Epidemiology of Lung Cancer // Annals of Global Health. 2019.Vol.85.No.1.Pp.1-16.

2. Grasso F., Frisan T. Bacterial Genotoxins: Merging the DNA Damage Response into Infection Biology // Biomolecules. 2015.Vol.5.No.3.Pp.1762-1782.

3. Minina V.I., Sinitsky M.Y., Druzhinin V.G., Fucic A., Bakanova M.L., Ryzhkova A.V., Savchenko Ya.A.,Timofeeva A.A., Titov R.A., Voronina E.N., Volobaev V.P., Titov V.A. Chromosome aberrations in peripheral blood lymphocytes of lung cancer patients exposed to radon and air pollution // European Journal of Cancer Prevention.2018. Vol.27.No.1.Pp.6-12.

4. Gomes S., Cavadas B., Ferreira J.C., Marques P.I., Monteiro C., Sucena M., Sousa C., Rodrigues L.V., Teixeira G., Pinto P., de Albreu T.T., Barbara C., Semedo J.., Mota L., Carvalho A.S., Mathiessen R.M., Pereira L., Seixas S. Profiling of lung microbiota discloses differences in adenocarcinoma and squamous cell carcinoma // Scientific Reports. 2019.Vol.9.No.1.Pp.1-11.

5. Druzhinin V.G., Matskova L.V., Demenkov P.S., Baranova E.D., Volobaev V.P., Minina V.I., Apalko S.V., Churina M.A., Romanyuk S.A., Shcherbak S.G., Ivanov V.I., Larionov A.V. Taxonomic diversity of sputum microbiome in lung cancer patients and it's relationship with chromosomal aberrations in blood lymphocytes // Scientific Reports.2020. Vol.10. Pp.1-12.

6. Wlordarska M., Luo C., Kolde R., d'Hennezel E., Annand J.W., Heim C.E., Krastel P., Schmitt E.K., Omar A.S., Creasey E.A., Garner A.L., Mohammadi S., O'Connell D., Abubucker S., Arthur T.D., Franzosa E.A., Huttenhower C., Murphy L.O., Haiser H.J., Vlamakis H., Porter J.A., Xavier R.J. Indoleacrylic Acid Produced by Commensal Peptostreptococcus Species Supresses Inflammation // Cell Host Microbe. 2017. Vol.22.No. 1.Pp.25-37.

7. Ertel A., Eng R., Smith S.M. The differential effect of cigarette smoke on the growth of bacteria found in humans. Chest. 1991.Vol.100.No.3.Pp.628-630.

\section{Lung microbiome composition specifity with respect to cytogenetical alterations in lung cancer patients}

V.Yu Buslaev ${ }^{1}$., V.I. Minina ${ }^{1,2}$., V.G.Druzhinin², V.P. Volobaev²., Baranova E.D²., P.S. Demenkov ${ }^{3}$

${ }^{1}$ Federal Research Centre of Coal and Coal Chemistry of Siberian Branch of the Russian Academy of Sciences, Institute of Human Ecology, Russia 650000 Kemerovo, Sovetskiy avenue, 18

${ }^{2}$ Kemerovo State University, Russia 650000 Kemerovo, Krasnaya street, 6

${ }^{3}$ Federal Research Centre of Institute Cytology and Genetics, Russia 630000 Novosibirsk, Academician Koptyug avenue, 2

*E-mail: vladislasbus2358@yandex.ru

Nowadays role of alterations in microbiota composition is actively considered in many pathologies including malignant ones. Donors with high level of chromosomal damage (over $3 \%$ ) were characterized by decrease of Peptostreptococcus bacterial genera representatives. This research allowed to detect and characterize the specific composition of adenocarcinoma associated lung microflora and establish relationship of its alterations with high level of genome damage in somatic cells of host organism.

Keywords: lung cancer; adenocarcinoma; microbiome; chromosomal aberrations. 